\title{
Imagined verbal transformations as a function of age and verbal intelligence
}

\author{
RICHARD S. CALEF, RUTH A. CALEF, EDWARD PIPER, and SHERI A. WILSON \\ West Virginia Wesleyan College, Buckhannon, West Virginia 26201
}

and

\author{
E. SCOTT GELLER \\ Virginia Polytechnic Institute and State University, Blacksburg, Virginia 24061
}

\begin{abstract}
The purpose of the present study was to investigate age and verbal IQ as factors influencing frequency of imagined verbal transformations (VTs). Words, sentences, and nonwords were presented repeatedly to children (ages 8-13) and young adults (ages 18-21), and the subjects reported experiences of hearing VTs. More VTs occurred for young adults than for children, and only for young adults was VT frequency directly related to verbal intelligence. For the children, VT frequency was inversely related to verbal IQ.
\end{abstract}

A number of researchers (Evans \& Kitson, 1967; Evans, Longden, Newman, \& Pay, 1967; Warren, 1968) have investigated effects of "stabilizing" an auditory stimulus on verbal transformation. A word undergoes illusory changes (verbal transformations) as a function of being repeated aloud a number of times. These verbal transformations (VTs) may range from imagining another word that rhymes with the actual stimulus word to perceiving extreme phonetic distortions.

Theoretically, VTs may occur because of a decrease in psychological and/or physiological "arousal" during word repetition. For example, Calef, Calef, Kesecker, and Burwell (1974), Evans and Kitson (1967), and Warren (1968) obtained results confirming the "arousal" notion by observing that phonetically complex words, less familiar words, and taboo words produced fewer VTs than did phonetically simple words, familiar words, and neutral words, respectively. In addition, Warren (1961, 1962) found that young adults (ages 18-25) reported more VTs than did elderly adults (ages 62-86) and nursery school children (age 5). If verbal repetition results in more boredom (i.e., less arousal) for more alert or intelligent individuals, then the findings concerning the age variable lend support to an "arousal" interpretation of verbal transformation.

The purpose of the present study was to test further the "arousal" hypothesis, that physiological and/or psychological "arousal" maintains the perception of an auditory stimulus, by investigating the frequency of VTs as a function of age (primary school vs young adults) and verbal intelligence (as measured by the verbal section of the Stanford-Binet Intelligence Test).

Reprint requests should be sent to E. Scott Geller, Department of Psychology, Virginia Polytechnic Institute and State University, Blacksburg, Virginia 24061.
We hypothesized that the number of VTs would be directly related to age and verbal intelligence, because repetition should produce the least arousal (or most boredom) for persons having the greater level of either variable.

\section{METHOD}

The children were 9 females and 11 males ranging in age from 8 to 13 years and attending French Creek Elementary School, French Creek, West Virginia. The young adults were 9 males and 11 females ranging in age from 18 to 21 years and enrolled in an introductory psychology course at West Virginia Wesleyan College. Eight stimuli-two sentences, four words, and two nonwords-were recorded on a cassette tape recorder and then re-recorded on high-fidelity tape so that each stimulus was repeated at a constant rate for a 5-min duration. The stimuli were presented in the following order: "our cider is good," "dress," "vinet," "police," "come to my house," "see," "books," "flime."

Specifically, subjects were told: "When I switch on the tape recorder, you will hear a word or sentence repeated a number of times. I want you to listen very carefully and quietly, and if you think you hear any change in the word or sentence, record a check mark on your data sheet, even if the change you hear does not resemble a recognizable word." (It should be noted, however, that subjects were not told to expect VTs as such.) Verbal stimuli were then presented in the above sequence and in the following manner. Each of the eight stimuli was repeated continuously for a 5-min period. Word and nonword stimuli were presented at a rate of 117 repetitions/min and sentences at a rate of 77 repetitions $/ \mathrm{min}$. Three-minute rest periods intervened between the 5-min presentation periods. This procedure was followed until the list of eight stimuli had been completed.

The subjects for the present study were selected from a sample of 90 children and 90 young adults, who were administered the Stanford-Binet Intelligence Test. All subjects were tested in one large soundproof room. The highest and lowest 10 scores for the primary children and for the young adults were identified as subjects. The study consisted of the high and low verbal groups for the two age groups (10 subjects/group). 
Table 1

Frequency of Imagined Verbal Transformations as a Function of Stimulus Type, Age, and Verbal IQ

\begin{tabular}{llcc}
\hline \multirow{2}{*}{$\begin{array}{l}\text { Stimulus } \\
\text { Type }\end{array}$} & & \multicolumn{2}{c}{ Verbal IQ } \\
\cline { 3 - 4 } & & Low & High \\
\hline \multirow{2}{*}{ Words } & Children & 54.05 & 36.95 \\
& Young Adults & 85.62 & 122.45 \\
Nonwords & Children & 16.8 & 12.9 \\
& Young Adults & 24.3 & 32.9 \\
\multirow{2}{*}{ Sentences } & Children & 77.3 & 44.7 \\
& Young Adults & 147.3 & 193.5 \\
\hline
\end{tabular}

Note-Verbal transformation entries were averaged across individuals per group and stimuli per stimulus type (i.e., four words, two nonwords, and two sentences).

\section{RESULTS AND DISCUSSION}

Table 1 shows that the group-average frequency of VTs per 5-min period (i.e., VT rate) for the words, sentences, and nonwords, respectively, was greater for young adults than for children. For each stimulus type, VT rate increased as a function of verbal IQ for young adults but decreased as a function of verbal IQ for children. A 2 (age) by 2 (verbal IQ) by 3 (stimulus type: words, nonwords, sentences) analysis of variance yielded a significant main effect of age $[F(1,36)=9.60, p<.01]$ and a significant Vérbal IQ by Age interaction $[\mathrm{F}(1,36)=$ $7.50, p<.05]$. No other effects were reliable $(p>.05)$. A Newman-Keuls paired comparison test was performed to interpret the Age by Verbal IQ interaction. This analysis indicated that young adults with high verbal IQ reported significantly more VTs than did young adults with low verbal IQ ( $p<.01)$; whereas children with high verbal IQ reported significantly fewer VTs than did the children with relatively low verbal IQ $(\mathrm{p}<.05)$.

Our data partially support the arousal hypothesis, that a lack of auditory stimulation will produce auditory perceptual distortions such as VTs. As in earlier studies (Warren, 1961, 1962), the present findings showed young adults to imagine more VTs than primary school children. According to the arousal notion, repetition should have produced more boredom for the young adults, hence more VTs. More importantly, however, there was a direct relationship between VT rate and verbal intelligence for young adults. Again, the arousal notion suggests that repetition should be more boring for the subjects with higher verbal intelligence. Indeed, an arousal notion suggests that a more intelligent individual (e.g., college adult with high verbal IQ) should possess a perceptual system less tolerant of boring stimuli and, thus, more prone to transforming the stimulus to achieve greater variation in stimulus input.

In contrast to the above confirmation of the arousal hypothesis, however, our study also found an inverse relationship between verbal intelligence and VT rate for primary school children. These results do not support the arousal hypothesis. One possible explanation for the contradictory results is that the arousal mechanism had not fully developed (either through maturation or learning) for the younger subjects and that attention was a more potent variable for the primary school youngsters. In other words, the children with higher verbal intelligence may have possessed a better attention span than lower verbal IQ subjects, and thus the higher verbal intelligence children were able to "hold" the perception of a word for longer periods of time (resulting in fewer VTs) than the lower verbal intelligence children.

The inverse relationship between children's VT rate and verbal IQ has applied implications for teachers of primary school children. For example, children who have relatively low verbal intelligence probably should not be given mass reading drills in which word stimuli are repeated. The present findings suggest that such students would not "hold" the perception of the word as well as would students with higher verbal IQ. Further research is necessary to discover more detailed explanations for the observed interactions between age and verbal IQ. Of particular theoretical and applied relevance would be research designed to determine at what age level the interaction disappears because of the maturation or conditioned development of the arousal mechanism. The measurement of verbal transformation tendencies offers one method for studying changes in such an arousal mechanism.

\section{REFERENCES}

Calef, R. S., Calef, R. A., Kesecker, M. P., \& Burwell, R. Verbal transformations of "stabilized" taboo and neutral words. Perceptual and Motor Skills, 1974, 38, 177-178.

Evans, C. R., \& Kitson, A. An experimental investigation of the relation between the "familiarity" of a word and the number of changes in its perception which occur with repeated presentation as a "stabilized" auditory image. National Physical Laboratory Auto Reports 36, 1967.

Evans, C. R., Longden, M., Newman, E. A., \& Pay, B. E. Auditory "stabilized images," fragmentation, and distortion of words with repeated presentations. National Physical Laboratory Auto Reports 30, 1967.

W ARREN, R. M. Illusory changes in repeated words: Differences between young adults and the aged. American Journal of Psychology, 1961, 74, 506-516.

WARREN, R. M. An example of more accurate auditory perception in the aged. In C. Tibbitts \& W. Donahue (Eds.), Social and psychological aspects of aging. New York: Columbia University Press, 1962.

WARREN, R. M. Verbal transformation effect on auditory perceptual mechanisms. Psychological Bulletin, 1968, 70. 261-270.

(Received for publication March 21, 1977.) 